\title{
The transcendental, the existential and the ethical: Alexy and Dworkin on the foundation of rights
}

\author{
DIMITRIOS KYRITSIs*
}

Lecturer in Law, University of Sheffield

\section{Introduction}

W hat do we expect from a theory that professes to furnish a justification for human rights? Which goals do we want it to accomplish and which theoretical and practical concerns do we want it to address? These questions are not meant to invite or presuppose a thoroughgoing philosophical pragmatism. Instead, they aim to alert us to the fact that we can make sense of human rights at different levels and from different perspectives cultural, historical, legal, political or philosophical, to name but a few - and, thus, that, depending on the level of detail our accounts are pitched to and the perspective we adopt, we ought to calibrate our theories accordingly. In other words, before we venture into this fascinating territory, we must be clear about our terms of reference.

The primary aim of this paper is to assess Robert Alexy's recent proposal for a discoursetheoretical justification of human rights. ${ }^{1}$ Alexy does not seek to justify human rights in terms of political expediency or usefulness. The justification he offers is, as one might say, foundational. His aim is to establish that human rights are firmly anchored in human experience; that we cannot just do away with them whenever it would be inexpedient or less useful to stick to them. For this reason, Robert Alexy lists a demanding set of properties of human rights - as we understand them - that he thinks alternative conceptions of their foundation ought to respect and account for. These properties thus serve as desiderata with regard to which we should on his view measure the success of our conceptions. A conception is for him pro tanto deficient, if it fails to tell a plausible story for the fact that we associate the concept of human rights with one or more of those properties.

So, let's take a closer look at Alexy's list of desiderata. When thinking about human rights, says Alexy, we ought always to bear in mind: a) their universal application to all persons; b)

\footnotetext{
MJur (Oxon), DPhil (Oxon). This essay forms part of a larger project co-funded by the European Social Fund and national resources entitled (EPEAEK II)-PYTHAGORAS II. I owe special thanks to George Pavlakos for extensive comments on a previous draft.

1 This proposal is primarily to be found in R Alexy, "Diskurstheorie und Menschenrechte", in R Alexy, Recht, Vernunft, Diskurs (Frankfurt a M: Suhrkamp Verlag, 1995), 142ff. That chapter was subsequently translated into English as R Alexy, "Discourse theory and human rights" (1996) 9 Ratio Juris 3(September), $209-35$. References will be made to the latter version (hereafter DTHR). The account was subsequently supplemented in R Alexy, "Menschenrechte ohne Metaphysik?" (2004) 52 Deutsche Zeitschrift für Philosophie 1, 15-24 (hereafter MoM).
} 
the fundamental nature of the interests and needs they stand for or protect; c) their abstractness; d) their moral force: and e) their priority. ${ }^{2}$ The first desideratum reminds us that the scope of human rights may not be truncated by appeal to geographical, cultural, racial or social circumstances. Such rights encompass all human beings just by virtue of the fact they are human. Justifications of human rights, thus understood, carry considerable ambition. They stand opposed to a group of theories that aim to tame them - and also blunt their practical edge - by restricting their applicability in various ways. Communitarians and historicists, as is well known, have pride of place in that group of theories.

Furthermore, human rights are not meant to protect just any interest human beings happen to have. Rather, they reflect interests that may reasonably be considered of the first importance for all human rights bearers. These interests typically correspond to very general features of what it means for someone to live well. The second and third desiderata allude to this property of human rights.

Finally, human rights, unlike rules of etiquette, are standards of special force. They belong to the realm of moral norms, that is, the norms that define the duties we owe one another (I take it that this is a widely shared definition of morality, but for our purposes nothing hangs on whether anyone adopts a different one). This is the import of the fourth desideratum. In addition to it, for Alexy human rights must be shown to enjoy some priority over other considerations; put differently, they must be shown to be equipped with a heightened moral force. As evidence of this priority, Alexy points to the power human rights are often recognised as having in constitutional democracies to defeat legal rules that are incompatible with them. ${ }^{3}$ But we can generalise this observation so as to make it apply to non-legal contexts as well. For instance, we may say, with Alexy, that although rights "can ... not only be limited because of other people's autonomy but also in favour of collective goods", 4 nonetheless "[a]utonomy does ... have a prima facie priority over collective goods", at least "in the form of a burden of argument in favour of individual autonomy and against collective goods". ${ }^{5}$ We need not settle for present purposes how exactly this priority is to be cashed out. ${ }^{6}$ It suffices to stress that, unless our theories provide a basis for assigning rights some kind of priority, they will have failed one crucial desideratum for a foundational justification of human rights.

Of course, not everyone accepts that we must take moral imperatives seriously. Many theorists assume what we might call a radically sceptical outlook toward morality. As a consequence, they are unlikely to be drawn to the idea that human rights are something we have strong reason to care for just by virtue of the fact that they reflect moral requirements. Alexy does not dismiss the radical sceptical challenge out of hand. In fact, he contends that part of the aim of a foundational justification of human rights is to provide the resources to rebut it. This is, in fact, one of the distinctive aspects of his approach. Alexy's theory starts from bracketing out the firm intuition most of us have that both morality and human rights matter. ${ }^{7}$ By contrast, heartened by an almost universal acceptance of human rights

2 MoM, p. 16.

3 MoM, p. 16.

4 DTHR, p. 226.

5 DTHR, p. 227.

6 Writing in the context of constitutional rights, Alexy has argued that rights function as principles, by which he means optimisation requirements. They give us a reason to realise them to the greatest extent that is a) factually possible and b) compatible with existing rules and the promotion of other principles, to which we are also committed. See his A Theory of Constitutional Rights, J Rivers (trans.) (Oxford: OUP, 2002), especially pp. 44-110.

7 MoM, p. 15. 
norms, many contemporary conceptions of human rights take all this for granted and proceed directly to explain what it is that makes human rights matter. In this article, much attention will be drawn to what this choice of stage-setting entails for Alexy's argument and its success.

It is not my intention to examine whether the list is exhaustive or whether it leaves out other important properties that we tend to attribute to human rights. Nor, in fact, shall I go into all the aspects of Alexy's intricate account. What I seek to do instead is suggest a couple of ways in which I believe Alexy's account falls short of generating the requisite philosophical support for two of the properties he mentions, namely the fundamental nature of the interests that underlie human rights, and the kind of force that we attach to claims based on them.

My argument will have the following structure. In the next section I shall present in some detail Alexy's proposal for a discourse-theoretical justification of human rights. I shall then launch two arguments that purport to show that this proposal does not meet the two desiderata mentioned above (sections 3 and 4). I will call them respectively the incongruence argument and the argument of force. Finally, building on some of Alexy's own remarks and then also drawing on Ronald Dworkin's theory of rights I shall outline an alternative model for a foundational justification of human rights (section 5).

\section{A transcendental argument for the foundation of human rights}

Robert Alexy invites us to distinguish two ways in which discourse theory may be employed in the service of a justification of human rights. One way, which he labels indirect justification, would be to stake out some human rights principle in an actual discourse that incorporates guarantees aiming to implement the general rules of discourse. If this principle is eventually agreed to under these discourse-friendly conditions, then the fact of our agreement is all the justification that our principle needs.

Alexy, however, is after what seems to be a more abstract and at the same time less contingent discourse-theoretical justification for at least some basic human right to liberty. It is a justification that will stand, however we decide to spell that right out in further detail. Alexy labels it direct, because it does not depend on any actual discourse having taken place. Rather, this type of justification starts from the fundamental presuppositions underlying all discourse and examines which attitude toward autonomy follows from these presuppositions, in the sense that an act or a norm that ran against that attitude would contradict the fundamental presuppositions of moral discourse. How would it contradict them? It would contradict them inasmuch as someone who performed an act or proposed a norm that was incompatible with that attitude would run into what is commonly referred to in the literature as a performative contradiction. He would be violating the norms that he is implicitly committed to just by taking part in discourse. Human rights, so established, would be in Alexy's terminology "discursively necessary in the narrower sense. Their nonvalidity [would be] discursively impossible in the narrower sense." 8

Before we proceed, we need to distinguish the argument that we will be focusing on from two further and related arguments that Alexy also advances to justify human rights. The argument we will be considering - the argument of autonomy, as Alexy labels it - is based on the idea of there being certain necessary presuppositions of genuine participation

8 DTHR, p. 221. See also R Alexy, A Theory of Legal Argumentation, R Adler and N MacCormick (trans) (Oxford: Clarendon Press, 1989), pp. $207 \mathrm{ff}$. 
in discourse 9 Unlike the argument of autonomy, the arguments of consensus and democracy rather start respectively from "assumptions about necessary and impossible results of discourses", 10 and the necessity of a democratic form of government for the best realisation of the demands of discursive rationality. ${ }^{11}$ Although I believe the two further arguments add considerable sophistication and supplement the general account, their assessment will have to wait for another occasion. I take it that the argument of autonomy is intended to have self-standing appeal and to explore a distinctive theoretical possibility, namely the possibility of a transcendental foundation of human rights. I therefore think that it merits special attention.

The distinction Alexy offers between direct and indirect justifications of human rights is part of a larger argument that aims to anchor human rights in discourse. So let me say a few words by way of situating Alexy's preferred direct justification of human rights in the bigger picture. The larger claim supplies a basis for the rules of discourse as well as an account of their normative force. It has two components, one transcendental and the other empirical. Let's take each one in turn. The first component establishes certain rules of discourse by way of a transcendental argument. For Alexy, transcendental arguments:

... consist of at least two premises with the following structure: The first premise identifies the argument's starting point, which consists of things like perceptions, thoughts, or speech acts, and claims that this starting point is necessary in some sense. The second premise then says that some categories or rules are necessary if the matter or issue chosen as starting point is meant to be possible. The final conclusion is that these categories or rules are necessarily valid. ${ }^{12}$

Such a transcendental exercise reveals that discourse, by which we mean the practice of asserting, arguing and asking, is underlain by a commitment to the equality and freedom of participants and also to universality (that is, a requirement that certain rules be extended to all human beings, at least in principle). Without such a commitment it would be impossible to make sense of the idea that in discourse "everyone can decide freely and equally about what she is willing to accept". ${ }^{13}$ It would also be impossible to make sense of our insistence that assertions made in discourse be backed by arguments, not intimidation, force, deception and the like, and also that they be justified in principle to everyone (so that nobody may be excluded from discourse).

The second component of the larger claim attempts to provide discourse - and thus also its rules, transcendentally derived - with a firm foothold in social life. It does this by, first, establishing the salience of discourse in the most general form of life. Indeed, few would object to Alexy's contention that:

[a]part from extremely unusual circumstances, such as growing up in total isolation, it is probably factually impossible to opt out of the most general form of life of human beings by never making any assertion at all however trivial, never putting forward any kind of justification, and never asking the question "why?", this counterpart to assertions and justifications. ${ }^{14}$

As Alexy readily admits, this fact does not suffice to ground a comprehensive and overriding interest in discursive resolution of social conflict. But it does seem to warrant the

9 DTHR, p. 227.

10 DTHR, p. 227, emphasis added.

11 DTHR, p. 233.

12 DTHR, p. 213.

13 DTHR, p. 211.

14 DTHR, pp. 217-18. 
more guarded claim that there exists among human beings a widespread - though obviously not unexceptional - and pervasive such interest, which induces people to engage in discourse.

This interest (argues Alexy) is, like any interest, linked to decisions about whether it will impose itself over other interests. These decisions have to do with the fundamental question whether we want to accept our discursive possibilities. They have to do with whether we want ourselves to be discursive creatures. These are decisions about what we are. ${ }^{15}$

The interest in correctness, in taking part in discourse aimed at arriving at universally acceptable and unenforced agreements, thus acquires what Alexy calls an "existential" hue. Besides, lacking such an interest, it would be difficult to imagine how our actual practices of discourse would be sustained over time.

Now, given that interest, claims Alexy, resort to argumentation can additionally be regarded as efficient and less costly than force. A person or a group of persons with such an interest will be more likely to acquiesce to policies that come attached with arguments rather than backed by the stick. Here Alexy appeals to considerations that would make argumentation an attractive strategy even for tyrants or other elites whose aim is to exercise power over a certain population. ${ }^{16} \mathrm{He}$ notes that the fact that tyrants and powerful elites may have recourse to argument out of strategic considerations, instead of a genuine sense of respect for citizens, and are all too willing to revoke this commitment when it no longer fits their purposes does not undermine the normative force of rules of discourse. Their validity does not hinge on the underlying motivation of participants (their "subjective validity" in Alexy's terminology), but rather on the web of attitudes and external behaviour that participants take to be called for when they join a discourse ("objective or institutional validity").

Granted then the two claims put forward in the preceding paragraphs - namely, first, that discourse transcendentally presupposes a commitment to universality and the equality and freedom of participants, and, second, that there is a strong (though not necessarily overriding) human interest in correctness - what follows about human rights? Remember that we are seeking to identify a direct justification of human rights, one that is not derived from outcomes of actual discourses. Alexy argues that, even at this level of abstraction, discourse properly understood may be said to ground a positive valuation of human autonomy. He quotes Carlos Santiago Nino who has construed the following "basic norm of moral discourse": "It is desirable that people determine their behaviour only by the free adoption of principles that, after sufficient reflection and deliberation they judge valid."17

For Nino, this norm follows from the assumption that "sincere participation in the practice [of moral discourse] implies assigning value to the free adoption of moral principles". ${ }^{18}$ Alexy, however, insists that we need to sharpen our understanding of sincere participation. It cannot be taken to entail simply an interest in "moral truth or correctness and in nothing else". 19 This understanding would not rule out cases where a respectful attitude in the context of discourse is coupled with reluctance to follow through discursively generated outcomes in actual practice. Alexy rightly points out that we would be offering a very weak foundation of human rights - or of any moral norm for that matter - if we were to allow their casual violation in reality, as long as lip-service is paid to them in the process

15 MoM, p. 21.

16 Alexy writes that only by establishing the existence of a general interest "can those who are merely interested in maximizing their advantage be bound sufficiently to the result of the transcendental argument" (DTHR, p. 213).

17 C S Nino, The Ethics of Human Rights (Oxford: Clarendon Press, 1991), p. 138.

18 Nino, The Ethics, p. 138.

19 DTHR, p. 223. 
of argumentation. To anticipate situations of this type, we need, argues Alexy, to beef up our set of assumptions by maintaining that participants take discourse seriously only if they are willing to solve their conflicts in accordance with discursively generated resolutions. ${ }^{20}$ With these assumptions in place, it seems to be only a short step to a general right to autonomy. When we manifest a willingness to adhere to discursively generated resolutions of social conflicts, we thereby tacitly recognise an interest on the part of our interlocutors to determine their own behaviour in accordance with principles that they themselves judge valid or correct or appropriate. Hence Nino's "basic norm". Further, if recognition of autonomy in the context of discourse is in the aforementioned sense necessary, ${ }^{21}$ it can be said to ground (or, in Alexy's terminology, "correspond directly to") a "general right to autonomy, which is the most general and basic right". 22 This Alexy formulates as follows: "Everyone has a right to judge for himself what is right and good, and to act accordingly." 23

What is the theoretical gain, if we couch the justification of human rights in terms of a direct justification flowing from the transcendental presuppositions of discourse? One advantage might be that by drawing on a feature of "the most general form of human life", namely discourse, and abstracting from the outcomes of particular discourses, a justification of this sort makes sense of the desideratum of universality. This feature marks out Alexy's justification from other possible approaches. One can here include justifications based on religious or cultural grounds and also on actual consensus. ${ }^{24}$ All of them suffer from particularism and are thus made vulnerable to the objection that they provide a foundation of human rights that applies only to those who share the requisite religious or cultural background or who happen to have agreed to uphold human rights principles.

But for Alexy there is a further reason that recommends his strategy. That is, it rescues the justification of human rights from an alleged charge of circularity. Alexy starts from the assumption that any justification of human rights that appeals to morality would be necessarily circular, and thus impossible. ${ }^{25}$ But he maintains that our predicament does not entail that our only alternative is evolutionary explanations about how our commitment to human rights and morality, more generally, came to arise - as he takes Nino to suggest. ${ }^{26}$

20 Here and throughout I assume that we are talking about discourses in the realm of action, that is, discourses for which it makes sense to say that their outcomes may be solutions to social conflicts.

21 For present purposes I ignore another crucial aspect of Alexy's analysis, which is his argument in favour of the necessity of law (see DTHR, pp. 220-1). My reason for doing this is that I am not so much interested in whether we must have a legal system of rights. My interest, one might say, lies with the "necessary demands to [law's] content and structure" (DTHR, p. 221) that general human rights principles impose, whether they actually shape its content and structure or not.

22 DTHR, p. 226.

23 DTHR, p. 226.

24 MoM, pp. 17-19.

25 DTHR, p. 212. Alexy makes reference to Nino here. He interprets him as regarding "the justification of [rules of moral discourse] as impossible as well as superfluous" (DTHR, p. 212). But I am not sure whether Nino's views can provide support for Alexy's contention. Nino does say that a justification of human rights will unavoidably depend on moral principles and therefore will not satisfy anyone who doubts whether he should care for morality at all. But his diagnosis is not that the project of moral justification is for that reason circular, let alone viciously so or even impossible. Rather Nino concludes that "[w] hat we must leave aside is the search for a non-moral justification of morality, since, according to the concept of justification that we actually employ, this is self-contradictory. The sceptic who maintains that, therefore, nothing constitutes a moral justification, is, as always, the frustrated seeker of unintelligible absolutes." (See Nino, The Ethics, p. 83.) There is, for Nino, just one type of justification of human rights, namely moral justification, and it's none the worse for that.

26 Again, it should be noted that although Nino does stress the importance of evolutionary explanations in an account of "why a society develops a moral system and a practice of moral discourse and why individuals tend to participate in that practice" (Nino, The Ethics, p. 83), he takes care to distinguish this type of account from any "justificatory claim". Justificatory claims must make appeal to moral principles. 
The transcendental argument he proposes seems to open up the third way. On the one hand, unlike evolutionary explanations, it can account for the normative force of human rights by connecting them to the rules of discourse (evolutionary explanations are notoriously incapable of generating a normative reason why we should carry on doing what we have been socio-biologically programmed to do). On the other, it stops short of a fully fledged moral defence of human rights, thus not falling prey to the (alleged) charge of circularity. The ideas of freedom and equality of participants are no doubt, as Alexy concedes, already value-laden. Yet, in his transcendental approach they are not derived from a moral theory of freedom and equality but from a reflection upon what is necessary for discourse, a salient feature of social life, to be sustained and make sense.

We can see here how this methodological modesty, as it were, ties back to the way Alexy conceives of the agenda for a theory of human rights. For him, remember, the debate over the foundation of human rights is not a family brawl. It is a much noisier affair. The reason is that it is not conducted solely among people who share a basic commitment to the importance of human rights. Our justifications of human rights must be directed to - and hopefully also engage - the sceptic, either of the local or the radical variety.

\section{The incongruence argument}

For the purposes of my critique it would be useful to introduce a distinction that the structure of Alexy's argument brings into sharp relief. This is the distinction between, on the one hand, a) autonomy in the wide sense and, on the other, b) autonomy in the strict sense. Autonomy in the strict sense encompasses all those attributes that good-faith participants in moral discourse ought to attribute to one another for moral discourse to be genuine. I call it a kind of autonomy because it is built around the idea that in ideal discourse a view prevails only if all participants to the discourse freely accept it, after due reflection and consideration and not through such devices as force, threat, manipulation, or misrepresentation. And this is no doubt an idea that is heavily informed by a principle of autonomy. By contrast, autonomy in the wide sense can, pace Rawls, be defined as one's ability freely to adopt, shape, revise and pursue a conception of the good, or pace Alexy, as "the individual choice and realisation of a personal conception of the good". 27 Elsewhere, Alexy has included within the range of human rights that he hopes to justify by appeal to discourse theory:

... the right to life and freedom from bodily harm and the rights to integrity of person, to basic freedom of action, of belief, of opinion and of assembly, to freedom of occupation and ownership, the right to basic equal treatment and participation in the process of the formation of political objectives [as well as] ... minimal basic social rights ... such as the right to a subsistence level. ${ }^{28}$

We may frame the distinction as one of subject matter, with one type of autonomy pertaining to moral discourse and the other, more broadly, to the full range of interests, needs and goals a person may have or embrace in the course of their life. Alternatively, we may couch the distinction as one between two statuses, on the one hand, the status of interlocutor in moral discourse and, on the other, the more comprehensive status of person. However we conceptualise the distinction, we can get a firm grasp of its purchase if we consider many of the preferences that we adopt in pursuit of our favoured conception of the good life, exercising our autonomy in the wide sense. Our having such preferences - like

27 DTHR, p. 209.

28 R. Alexy, "A discourse-theoretical conception of practical reasoning" (1992) 5 Ratio Juris 3(December) 231-51, p. 246. I will hereafter assume that the term "individual choice and realisation of a personal conception of the good" captures at least some of the most important of the rights enumerated in the text. 
the preference to marry Suzie rather than Laurie - and acting on them is not directly implicated by our participation in discourse. Undoubtedly, we can imagine a discourse where someone puts forward the claim that we ought not autonomously to form preferences of this sort and that others may legitimately impose on us something that runs contrary to our preferences - they may oblige me to marry Laurie instead of Suzie. We would then have to defend not our preference itself but our being able to form and act on it, if we so please (assuming, of course, that the other party is likewise disposed). To make our case, we would also require that our autonomy in the strict sense be respected, for otherwise the discourse would be rigged. Nonetheless, that would be a case where our autonomy in the wide sense has become the subject of discussion, not one where the two types of autonomy have merged into one. Likewise, I don't mean to deny that the status of interlocutor may in many cases be itself ethically or morally loaded. In fact, it typically is. Imagine discussion in a political forum. We have the firm conviction that exclusion, intimidation or deception in discussions of this sort compromises the moral status of citizen. But again, in such cases the reason for the special ethical or moral importance of the status of interlocutor comes from the circumstances and the social role of specific types of discourse, and not from the transcendental presuppositions of discourse in general.

It is important not to lose sight of this distinction, not only for the purpose of the critique I am about to mount but also more generally for the sake of better understanding the structure of Alexy's argument. Alexy's argument would be hopelessly short-circuited if it were based on the assumption that the rules and presuppositions of moral discourse actually amount in themselves to a full-blown principle of autonomy in the wide sense. For, we intuitively want to distinguish the status of interlocutor from personhood. However fundamental we take discourse to be in our lives and however radical we think the consequences would be if we retreated from it completely, ${ }^{29}$ it surely does not take up all our lives. We don't spend our entire lives asserting claims or engaging in resolution of social conflicts, and a theory that entailed that picture of our lives would no doubt sound deeply counter-intuitive.

As I have already noted, this is not an argument against Alexy. Alexy is conscious of the distinction and his claim is precisely aimed at finding a bridge that takes us from respect of autonomy in the strict sense to respect for the wider autonomy as well. He writes: "On the first level [the discourse-theoretical justification of human rights] must substantiate the rules of practical discourse in order to justify, on a second level, the human rights on these grounds." 30 The incongruence argument that I am about to present questions this bridging effort. It takes for granted that discourse presupposes strict autonomy and instead asks: does participation in discourse with its concomitant notion of strict autonomy involve or imply any specific attitude toward autonomy in the wide sense? I shall argue that it doesn't necessarily have such implications. I have suggested above that the incongruence argument takes issue with the extent to which Alexy's theory can accommodate the fact that we associate human rights with certain fundamental human interests. I take it that the interests underpinning

29 Alexy quotes Apel who associates retreat from argumentation with the loss of "the possibility of selfunderstanding and self-identification" and with "self-destruction". See K-O Apel, "Das Apriori der Kommunikationsgemeinschaft und die Grundlagen der Ethik", in K-O Apel, Transformation der Philosophie, vol. 2 (Frankfurt: Suhrkamp, 1973) p. 358ff., p. 414. Habermas goes even further and talks about "schizophrenia and suicide" (J Habermas, "Diskursethik. Notizen zu einem Begründungsprogram", in J Habermas, Moralbewußtsein und Kommunikatives Handeln (Frankfurt: Suhrkamp, 1983) p. 53ff., p. 112). Alexy, as we have seen, opts for the more modest suggestion that participation in discourse is necessary for taking part in the most general form of life of human beings (DTHR, p. 217).

30 DTHR, pp. 210-11. 
autonomy in the wide sense illustrate this feature of human rights, and thus that failure to generate philosophical support for them is a serious failing vis-à-vis this specific desideratum.

Let's consider the following example:

\section{The stranger-in-the-train example}

Jack, a professional moral philosopher, takes the train home. Jill, a complete stranger, sits in the same compartment. It turns out that she also takes a lively interest in moral philosophy. She tells Jack she has been thinking about the trolley problem lately. Jack reluctantly engages in a discussion over it. At the outset they disagree. However, they exchange arguments in good faith and finally come to agree that the one person should be sacrificed. At that point, the train arrives at Jill's stop, whereupon she gets off. They never meet again.

The stranger-in-the-train example aims to tease out the following intuition. Moral discourse does not necessarily bring in its train the load of presupposition regarding the autonomy of the interlocutors that Alexy and Nino seem to suppose. Let's see why. Although Jack and Jill debate an issue that no doubt belongs to the realm of action, they need presuppose - or respect, for that matter - little more than autonomy in the strict sense, in order to make their discussion meaningful. That is so for at least two reasons. First, consider the topic of Jack and Jill's discussion. Even if they take the trolley example seriously and their agreed upon solution as the morally right one, it is not entirely clear how any belief that they might come to have on this issue can affect the way they view their standing vis-à-vis one another in contexts other than the limited one of their discussion. The connection between autonomy in the wide sense and discourse would obviously work better in situations where the topic of discussion more closely engages one's conception of the good life. But, as already suggested, Alexy's claim would be gaining illicit support, if it depended on the topic of the discussion.

Second, the example is thus set to ensure that Jack and Jill know nothing about each other's lives and, as typically happens, they may safely assume that they need not - in a matter of hours they will part for ever. Although both appreciate the fact that the other is responsive to good arguments and neither makes an effort to deceive or force the other into accepting a position they disagree with, they can be agnostic about how the other conducts their own lives, whether, indeed, they have an interest in determining their behaviour "only by the free adoption of principles that, after sufficient reflection and deliberation, they judge valid". 31 The fact that they have such an interest, when it comes to the trolley problem, does not entail an analogous interest in other spheres. Indeed, something quite different seems to be the case. That is, their interest seems to stem from their commitment to solve a difficult practical problem together rather than from any interest in enjoying their autonomy in the wide sense - at least not necessarily so. It may of course be that in the course of their discussion they will invoke notions about the distinctness of persons in order to account for their intuitions regarding the trolley problem. And it may be, further, that these notions will eventually lead them to adopt jointly some principle of personal autonomy. This consensus is of course not to be denigrated. However, it is not what Alexy has in mind. For, their consensus on the principle of personal autonomy would at best furnish an indirect justification of personal autonomy, one that is contingent on the actual discourse.

But this line of argument may be objected to on the grounds that I have rigged my example. I have taken a peripheral case of moral discourse, which diverges from the standard case, insofar as Jack and Jill have an interest "in correctness or moral truth and in

31 Nino, The Ethics, p. 138. In making reference to interests at this point, I don't mean to commit myself to what has been called the interest theory of rights, or to any more specific theory of rights for that matter. I use the term "interest" in a philosophically loose sense. 
nothing else"; they do not necessarily want "to solve social conflicts through discursively generated and controlled consensus". 32 This, recall, is for Alexy the benchmark that determines serious participation in moral discourse. Now, to begin with, there is nothing in the nature of the example that precludes Jack and Jill from having or developing something like the attitude Alexy refers to, at least in the sense of a standing disposition to act as one has agreed it is right to act if one happens to face a situation of the sort that is the subject of discussion. The fact that it is a highly unlikely situation - that one would find oneself in a position where it was necessary to decide between sacrificing one person or five by directing the train to one of two tracks - does not, it seems to me, make it the case that deontologists and consequentialists do not take their disagreement seriously in Alexy's sense. However this may be, I believe the problem persists in other, less stylised, contexts as well. So let's turn to one such context.

\section{The obnoxious neighbour example}

Harvey shares a fence with Stanley. Stanley persistently raises disputes about how to set the boundaries between them, who must pay to mend the fence and so forth. However, he proves extremely accommodating in negotiation. Apart from that, Harvey and Stanley lead completely separate lives.

The obnoxious neighbour example models a situation of social conflict, where both parties to the dispute have the right kind of attitude toward one another as far as discourse theory goes. However, it still seems somewhat far-fetched to say in this situation that Harvey and Stanley need attribute autonomy in the wide sense to each other if they are seriously to participate in moral discourse. They can, I think, resolve their fairly circumscribed disputes drawing on a limited type of attitude that in no way implies anything about how they view the rest of one another's lives.

It gets worse. Consider the following complication to the obnoxious neighbour example. Let's suppose that Harvey never gets to meet Stanley. For, whenever Stanley wants to create trouble, he instructs his lawyer to notify Harvey and conduct the negotiations on his behalf. Surprisingly, Stanley's lawyer is quite reasonable in his dealings with Harvey. $\mathrm{He}$ knows that Stanley is pathologically fussy; Stanley does not so much care to win the argument as to settle things - all the things he pathologically thinks need settling. In this variant of the obnoxious neighbour example, Harvey has little reason to take his interlocutor's autonomy in the wide sense into account. In fact, for the purposes of the discourse, he has little reason to suppose that his interlocutor, the lawyer, has any life of his own. For all he knows, Stanley may have the lawyer locked up in the closet and only let him out when he needs someone to defend his interests. That is because the terms of reference of the discourse involve only an appeal to the interests of Stanley. The interests of the lawyer drop from the picture. This complication reinforces, I believe, a suspicion that much of the prima facie plausibility of Alexy's proposal comes from the fact that certain - indeed many instances - of discourse deal with problems that engage one's ability autonomously to lead one's life. This is a problem for Alexy, because he wants to derive his justification of human rights from the very notion of participation in discourse, and not from what the subject of discourse happens to be.

To repeat a point made earlier, this is not to say that there must be a perfect fit between the full-blown list of human rights that are currently recognised in liberal societies and the type of concern that we find presupposed in moral discourse. I don't think Alexy is committed to anything like this rather strong claim, nor is the thrust of my argument based on the assumption that he should be. I would obviously be making a bad argument if it 
boiled down to pointing to examples where a discourse establishes the importance of freedom of speech but not privacy. I readily agree that Alexy would be right to insist that he has made his case just as long as he has established that we could plausibly move from an examination of the fundamental presuppositions of moral discourse to a general and largely unspecified right to liberty. So, all I am saying is that there must in any case be a plausible connection between the role of interlocutor in moral discourse and the status of person entitled to certain basic liberties independently of moral discourse. Otherwise, the bridge from the prerequisites of moral discourse to a general principle of respect for one's autonomy (of the type I have labelled autonomy in the wide sense), however abstract we take that principle to be, collapses. The examples I have offered aim to sever this connection. They suggest that there may well be cases where moral discourse solely involves a narrow set of discourse-bound presuppositions that have no necessary bearing on one's attitude toward other people as far as their broader life, their status as persons and not interlocutors, is concerned.

At this point it may be objected that in setting out my counter-examples the way that I did I focused on specific - and rather peculiar - instances of discourse rather than practices of discourse. But, the objection goes on, if we turn to the social world, we are more likely to see that individuals engage in complex and sometimes wide-ranging practices of moral discourse that comprise many instances of discourse in very different contexts. It would certainly strike us as odd if someone's only experience of moral discourse came from random encounters in trains. Appeal to practices of discourse thus opens up the space for the defence that, in the course of one's engaging in such practices, peculiarities and aberrations pertaining to one type of setting may be compensated by participation in others.

Now, although the objection offers a very plausible characterisation of how individuals are actually steeped in moral discourse, it does not save the relevance of the discoursetheoretical argument for the purpose of the discussion. Transcendental arguments, we have seen, do not start from actual discourses having taken place. Instead, they elaborate what all discourse, any discourse, must presuppose, so that it may be conducted successfully and genuinely. By contrast, the sort of experience that being immersed in practices of discourse involves is in a very strong sense contingent. It does depend on actual discourses having taken place, although, of course, not on those discourses having produced certain results rather than others (as would be the case if we were attempting an indirect justification of human rights).

\section{The argument of force}

We have seen that one of the salient features of our understanding of human rights is that they have the force of moral requirements - in fact, requirements of considerable stringency. We tend to think we are morally obliged to care a great deal about human rights. This feature is encapsulated in the desiderata of moral force and priority. Following up on the argument of the previous section, I now want to argue that in fact Alexy's theory does not adequately square these desiderata, and primarily the former. The thrust of my argument in this section will be this: even if we managed to solve the incongruence problem, Alexy's account would still be vulnerable to the objection that it does not account for the special moral strength we are inclined to attribute to claims based on human rights. Before we begin, it would help to have in hand an upfront formulation of the argument:

Recall Nino's "basic norm of moral discourse": "It is desirable that people determine their behaviour only by the free adoption of principles that, after sufficient reflection and deliberation they judge valid." 33 In the previous section it was argued that the fact that we

33 Nino, The Ethics, p. 138. 
may accept such a norm for the purposes of discourse and within its context does not mean that it need hold in other contexts, at least not for that reason. But we have to examine further whether acceptance of the basic norm of moral discourse by interlocutors in the above sense would anyway provide a compelling - though not necessarily always overriding moral reason to respect human rights. I shall claim that it doesn't.

What are we after when we say that acceptance of the basic norm is compelling? Here is one suggestion: many theorists, including Alexy, point out that discourse belongs to the most general form of human life. Hence, it is in an important respect non-optional or necessary to engage in it. One may here recall the dramatic images that discourse theory invokes to convey the consequences of not taking part in any form of discourse whatsoever. The problem with this suggestion is that it mistakes two ways in which something or other might be non-optional. First, doing $x$ might be non-optional in that I am morally required to do it (we can substitute morality with law or some other normative system). Second, doing $x$ might be non-optional in that it is in some way intractable. So, for instance, I find it intractable to procrastinate. When I don't, I break down. But, obviously nothing in the realm of normativity follows from my tendency to procrastinate. It doesn't seem to me to make much of a difference if in the place of procrastination we put a rulegoverned activity. A person might feel compelled in the second sense to play football on Sundays with his or her friends. Once that person starts playing football, he or she must no doubt follow the rules (and then be required in the first sense to do certain things). But there is nothing in this intractable desire to play football that makes the rules of football enjoy a heightened normative force (not, that is, for that reason).

In the previous paragraph I argued that "intractability" of the sort discourse theory associates with participation in the practice of discourse does not deliver the right kind of compellingness. It might now be objected that I have relied on too narrow an understanding of the importance philosophers like Alexy attribute to discourse. In support, it might be reminded that Alexy does not simply point to the pervasiveness of practices of discourse but instead goes to great lengths to establish the existence of a significant - indeed existential - interest in human beings to engage in such practices. He further argues that Machiavellian power-seekers also have an interest in at least pretending to be playing along and manifesting the attitudes that participation in discourse brings in its train as required. It goes beyond the scope of this paper to assess the argument Alexy advances to the effect that those who use argumentation as smokescreen share this interest in sufficiently strong form. I am after what I take to be a deeper ambiguity in Alexy's project. So, for present purposes, I shall assume the correctness of that argument and also of the argument that human beings by and large have an interest in engaging in discourse of the sort Alexy claims. I shall only examine what conclusions we may legitimately draw from these assumptions.

Upon closer inspection, it appears problematic to make the move from an interest, however substantial, in engaging in discourse to a strong moral commitment to respecting the autonomy of one's interlocutors. We are well acquainted with justifications of human rights in terms of interests and I will say something about this methodology in the next section. But Alexy's version of a connection between interest and human rights that was sketched in the previous paragraph diverges from that familiar approach. It doesn't identify certain interests which human rights are then taken to protect. Rather, it postulates an interest to take part in a practice, which practice is alleged transcendentally to presuppose a commitment to respect those rights. Nor, importantly, does Alexy's version suppose that the normative force we end up attributing to respect for rights is derived from the instrumental value such an attitude would have in enhancing discourse. To propose this instrumentalist justification would be to say that the value of human rights lies in their ability to facilitate 
discourse. In some contexts (like democratic decision-making), such an instrumentalist justification might have some plausibility. And indeed, in some form or other it has been proposed by way of a defence of a set of constitutional rights. But it would be much more ambitious to subordinate autonomy in the wide sense to autonomy in the strict sense across the board - to say that we respect human rights just (or even primarily) in order to facilitate general discourse - and Alexy says nothing to align himself with this rather extreme view.

We have so far said a couple of things about what Alexy's version of the connection between interest and human rights does not mean. Can we say anything more informative about it though? To make progress with this question, we may take a lead from Benjamin Constant's famous assertion that "commerce inspires in men a vivid love of individual independence". ${ }^{34}$ I take it that Constant does not just mean that commerce inspires in men a commitment to the freedom to do business. And he definitely does not mean that, if asked why autonomy matters to them, merchants may sensibly say that it matters by virtue of the fact that they engage in commerce or even that they have an interest to do so. $\mathrm{He}$ probably has in mind something like the following claim: a practice like commerce alerts us to the value of independence and illustrates its importance not just for the purposes of commerce but in general. It helps us appreciate individual effort and judgment, it imbues in us a desire to stand on our own two feet etc. When in the course of engaging in commerce we come to see the value in all these things, we recognise that they must also have appeal to those who never did and never will be involved in trading. ${ }^{35}$ Likewise, we might say, discourse reveals something about the desirability of autonomy in the wide sense that might otherwise be concealed. Indeed, unlike commerce, discourse is a practice we all take part in.

The problem is that, as in Constant's example, commerce itself does not figure in the justification of the value of independence, so discourse cannot furnish a (direct) normative basis for autonomy in the wide sense (at least on this reading of the connection between discourse and human rights). Let me sharpen this statement. Discourse has rules, of course, and any interest we might have in engaging in it is no doubt a normative basis for the force of those rules in the context of discourse, much in the same way that economic self-interest may be understood to provide (some) normative basis for our respect for the rules of trade. But we want to go beyond that. We are interested in autonomy in the wide sense and we want to be able to cite a reason for our respect for it. To this effect the Constant-inspired reading of Alexy's proposal is of no avail. The relationship between commerce and independence may be regarded as genealogical, so to speak, but not foundational in the normative sense.

But do we really want to go beyond that? Are we really committed, in offering a foundational justification of human rights, to producing reasons for the compellingness of human rights? What would be the problem if we didn't achieve this? Let me repeat what I think we are presumably trying to achieve by following Alexy's path. Arguably, we take seriously the sceptical charge that we shouldn't care for human rights at all either because we don't belong to a community where respect for freedom and equality is widely and

34 B Constant, Political Writings, B Fontana (trans. and ed.) (Cambridge: CUP, 1989), p. 315. The quote continues as follows: "Commerce supplies their needs, satisfies their desires without the intervention of the authorities. Their intervention is almost always - and I do not know why I say almost - this intervention is indeed always a trouble and an embarrassment. Every time collective power wishes to meddle with private speculations, it harasses the speculators. Every time governments pretend to do our own business, they do it more incompetently and expensively than we would."

35 Of course I may be wrong in my exegesis of Constant's thesis, but this does not seem to me to affect the argument of this section. We can envisage the type of claim I describe in the text, regardless of whether we then attribute it to Constant or not. 
institutionally accepted or because we don't care for morality. We give an account of the salience of human rights by appealing to a practice and a corresponding interest, which few could seriously question are universal, and thus rebut the sceptical move.

This shift of attention, however, comes at a substantial cost. Importantly for present purposes, by focusing on universality we lose sight of another goal of justifications of human rights, the desideratum of special moral force. To go back to a previous example, it may be that I have a vital interest in playing football on Sundays with my friends. Our football sessions relieve me from the stress of the week. They provide me with muchneeded physical exercise and, besides, they are fun. Now, after a number of such sessions it comes to pass that playing football with my friends also strengthens our sense of camaraderie. But clearly, playing football does not add anything to the reasons I have - or should have - to hold camaraderie among friends in high regard. Suppose someone comes up to me and inquires why they shouldn't betray their friends when the opportunity arises. To talk that person out of this idea, it's no use pointing to my Sunday football sessions - let alone the interests I have in attending them. Or suppose someone acknowledges that camaraderie has value, but insists that it is a value that is easily outweighed by considerations of the slightest inconvenience. Again, unless I have independent reasons to offer about the centrality of camaraderie in relationships between friends, I will do a poor job at convincing that person if I merely recount the story of my Sunday football sessions.

But maybe, contrary to what I argue, Alexy is happy with that. Maybe that's all a direct justification of human rights is meant to supply. It points to a pervasive, distinctly human practice that, of necessity, sustains adherence to human rights norms, whatever "sustain" is taken to mean (recall that I am here assuming that the obstacle of incongruence has been overcome). Thus, at an abstract level it does manage to garner some support for respect for human rights. It need not also furnish reasons that we can employ in actual discourses to back our more specific claims about the application or force of human rights. ${ }^{36}$

Now, whatever the merits of this proposal, it is not, I believe, an accurate description of Alexy's position. Alexy, we have seen, wants to account for both the moral force and the priority of human rights. He explicitly states that the right to autonomy, established by means of the argument we have examined in this article, has not only prima facie force, but also prima facie priority, ${ }^{37}$ and I think he is right to insist on that. When we try to justify our adherence to human rights, we seek to establish not just that we feel a normative pull to respect them, but at a minimum that they are of some special importance. ${ }^{38}$ Thus, to make his case, it seems that Alexy must do more than just point to the fact that some respect for human rights is presupposed by our participation in practices of discourse. He must be able to say something about the place human rights occupy in our moral universe and the relation in which they stand to other values in moral argument. But the proposal of the previous paragraph would have Alexy delegate all such questions to the level of actual discourses. It thus invites us to narrow seriously the scope of Alexy's argument and consequently also its relevance to our philosophical and political concerns.

36 I am indebted to George Pavlakos for impressing upon me the need to address this objection.

37 DTHR, p. 227.

38 I have tried to put the point in as modest a form as possible. Of course, I am not saying that Alexy need come up with a metric that settles cases of conflict between human rights and other values. 


\section{To the rescue: An ethical foundation for human rights}

Recall Alexy's point of departure. His transcendental argument, he says, is preferable, because, among other things, it supposedly avoids the circularity plaguing accounts that seek to ground human rights in morality. Now, this is not, strictly speaking, accurate. A fully moral justification of human rights is not circular, just in case it grounds human rights in a moral idea that does not presuppose the moral value of human rights. There is, it seems to me, no shortage of such moral ideas. But Alexy, we have seen, uses circularity in an idiosyncratic way. For him, moral justifications of human rights are circular in the sense that they must of necessity appeal to moral principles, thus not engaging the radical moral sceptic, who is indifferent to morality in general. To counter the radical sceptical position, as construed above, we then do well to invoke another approach that takes a broader view of the practical domain and generates the requisite philosophical support for human rights by recourse to very general ethical ideas about what it means to live a good life. I shall call this the ethical approach and I shall take Ronald Dworkin's recent articulation of the idea of liberal equality to exemplify it. The ethical approach has an advantage that is relevant to the theoretical concerns driving Alexy's thinking on these matters. It does not take the bindingness of morality for granted but instead addresses the question why we should care for human rights together with the more fundamental question about whether we should care for morality in the first place. It integrates both questions in an account of the good life. ${ }^{39}$ It thus does not evade the sceptical charge. It purports to face it head on. Here is a characteristic formulation of the project, as Dworkin understands it:

[A] theory of political morality ... should be located in a more general account of the humane values of ethics and morality, of the status and integrity of value, and of the character and possibility of objective truth. ${ }^{40}$

The connection between ethics and morality is further highlighted in the following sentence:

We should hope, moreover, for a theory of [the central political values] that show them reflecting even more basic commitments about the value of a human life and about each person's responsibility to realize that value in his own life. ${ }^{41}$

Dworkin identifies two principles which he believes underlie the domain of ethical and moral value. He calls them the two principles of ethical individualism. The first, the principle of equal importance, states that "it is important, from an objective point of view, that human lives be successful rather than wasted, and this is equally important, from that objective point of view, for each human life". ${ }^{42}$ The second principle, which he labels the principle of special responsibility, he summarises as requiring that "though we must all recognize the equal objective importance of the success of a human life, one person [has] a special and final responsibility for that success - the person whose life it is". ${ }^{43}$ Dworkin invites us to consider whether we can sensibly reject either of these principles, quite independently of how they are further fleshed out. If, as he supposes, the two principles are

39 Dworkin's approach might be thought to give rise to a charge of circularity at a higher level, insofar as it also defines certain ethical ideas in the light of moral ones. To meet this charge adequately, we would have to explore Dworkin's general interpretive methodology, which he places front and centre of moral reasoning. But such an inquiry would go far beyond the scope of this paper.

40 R Dworkin, Sovereign Virtue: The theory and practice of equality (Cambridge Mass.: Harvard UP, 2000), p. 4. The structure and details of this project are further analysed in his John Dewey Lectures delivered at Columbia University in 1998 under the title "Justice for hedgehogs".

41 Dworkin, Sovereign Virtue, p. 4.

42 Dworkin, Sovereign Virtue, p. 5.

43 Dworkin, Sovereign Virtue, p. 5. 
indispensable in our thinking about ethical and moral value, we must then proceed to see how best to make sense of them in the light of each other. This task Dworkin pursues in many different directions and in the course of so doing proposes and defends the fundamental tenets of his own preferred conception of political morality, liberal equality. It would be impossible here to do justice to this complex enterprise. What I shall try to do instead is present one line of argument that I consider pertinent to the aims of this paper. This is the argument Dworkin provides in order to derive something like a general right to autonomy from an account of certain general conditions of living well.

Dworkin claims that the concept of success in one's life, the concept of living well, is governed by the challenge model. The challenge model states that "the goodness of a good life lies in its inherent value as a performance". 44 The performance, in turn, consists in the way one responds "to one's situation", 45 to the challenge of living well under the circumstances that one faces in one's life. On this model, then, a life is well spent, if the person whose life it is has made something good of their social position, skills and talents, the adversities and the opportunities that had to be reckoned with, and having been born in a certain period in history and in a certain place etc. Dependence of a life's value on one's situation, the fact that, to use Dworkin's apt term, this value is in such a way "indexed", 46 provides some of the explanation for our tendency to recognise value in very different lives. In one case, we may admire someone's success in combining career and family life. In another, we may appreciate the way someone has succeeded in overcoming a serious disability. The challenge each one of us faces is sensitive to our widely varying predicaments, our singular "places in the world".

With this conception of the good life in place, Dworkin then goes on to argue that "liberal equality does not preclude or threaten or ignore the goodness of the lives people live, but rather flows from and into an attractive conception of what a good life is". 47 It is this argument that furnishes the connection between his account of the good life and the concerns of this article, so we need to take a closer look at it. At first sight, there appears to be cause for suspicion. Dworkin's account focuses on persons who care about what he calls their "critical interests", namely their interests in "having or achieving what it makes [their] life a better life to have or achieve". ${ }^{48} \mathrm{He}$ contrasts our critical interests to our volitional interests. "Someone's volitional well being is improved," he writes, "when he has or achieves what he in fact wants." 49 So, unlike our volitional well-being, we cannot improve our critical well-being just by wanting something that we then get. It must be the case that what we get really makes our life better, given our circumstances. This is a judgment we can be wrong about. We may fail to identify what promotes our critical interests in the first place, or, even if we do identify it, we may fail appropriately to respond to it.

Would it then be ethically acceptable for others to impose on us the course of action that supposedly best tracks our critical interests every time they think we are mistaken about them? To answer this question affirmatively would be to accept, at least in principle, the legitimacy of paternalism. Such a concession, however, would seriously truncate individual autonomy. Now, the road to strong forms of paternalism is sometimes blocked by epistemic or pragmatic considerations, for example that, however fallible, we are better

44 Dworkin, Sovereign Virtue, p. 251.

45 Dworkin, Sovereign Virtue, p. 260.

46 Dworkin, Sovereign Virtue, p. 259.

47 Dworkin, Sovereign Virtue, p. 242.

48 Dworkin, Sovereign Virtue, p. 242.

49 Dworkin, Sovereign Virtue, p. 242. 
judges of our own good than anybody else, or that granting this sort of power over our lives to other people would open the way to abuse. But Dworkin offers an argument of principle in favour of autonomy and against paternalism that he draws from the challenge model. He claims that the challenge model favours a strong - in fact constitutive connection between a life well spent and a personal conviction that it was indeed so. Someone cannot be credited with a successful performance, unless he intended what he did. Likewise, we cannot think someone has lived well who does not endorse and even regrets the things he does. Thus, the challenge model of ethics assigns a high value to ethical integrity, the state where someone "lives out of the ethical conviction that his life, in its central features, is an appropriate one, that no other life he might live would be a plainly better response to the parameters of his ethical situation, rightly judged". 50 On the challenge model, lack of ethical integrity does not just make one's life pro tanto worse; rather, ethical integrity is assumed to enjoy special priority, in the sense that "a life that never achieves that kind of integrity cannot be critically better for someone to lead than a life that does". ${ }^{51}$ In the course of one's life one may realise important values - one may produce sublime art, for instance, or change the fate of the nation for the better - but if one's life scores very low on ethical integrity, it cannot be considered superior - better spent -to a life that scores higher on this count, even if the latter has no comparable artistic or political achievements to commend it.

I do not pretend to be offering here more than a rough sketch of Dworkin's sophisticated account. But even this rough sketch makes plain the structure of the argument. By assigning ethical integrity absolute priority over other dimensions of value (in the determination of the goodness of a life), Dworkin seeks to offer individual autonomy a solid justification. We have rehearsed how the priority plays out in the case of paternalism, but the point is more general. If we are to be able to live well, it is necessary (though by no means sufficient) that we can make decisions for ourselves and act on those decisions without undue interference from other people, even if that interference is motivated by a belief that a different decision is better for us. Thus, we have to be able to choose from among the careers that are reasonably open to us - given the circumstances - the one we think best suits us; to pursue the type of intimate relationship that we find fulfilling; to be free from force in forming our own beliefs about the sacred and living the life that accords with those beliefs and so forth. In short, we have to be able to do all the things that comprise autonomy in the wide sense. It is quite evident that something like the recognition and guarantee of a right is a way to give expression to the importance of ethical integrity for our well-being. Of course, rights are not under threat solely from paternalistic attitudes and policies. Someone might lock us up just because that would further that person's own interest, narrowly conceived. But if ethical integrity is compromised, whenever we are forced to adopt an "objectively worthwhile" life-style we despise, it goes without saying that it is compromised in cases like this as well.

So, on the challenge model, a strong commitment to autonomy - and thus also to the rights that guarantee it - flows from the value of living well. We value autonomy because we have a stake in leading a rewarding life and because it is necessary for this that we live it in accordance with our convictions about what would make it go best, rather than against them. In this sense, Dworkin's account succeeds where Alexy's has failed. The foundation for human rights Dworkin proposes encompasses the range of fundamental interests that we tend to associate with them; it is thus impervious to the incongruence argument. And it also equips claims of human rights with the kind of moral force we intuitively believe they

50 Dworkin, Sovereign Virtue, p. 270.

51 Dworkin, Sovereign Virtue, p. 270. 
must enjoy, thus addressing the argument of force. It says we care for human rights insofar as we have a strong reason to care for our well-being, because to violate autonomy entails a significant harm in the quality of life we lead that does not disappear just by an increase in the value thereby produced. In fact, the assignment of absolute priority to ethical integrity helps us get a grip of the heightened strength we attribute to claims of rights. We might even say that, like Alexy, Dworkin proposes an existential foundation for human rights, in the sense that he proceeds from an account of what it is for persons to live their lives, to be the beings they are. Unlike Alexy's, however, his account is such that, if we adopt it, we will be in a position to cite important reasons for our adherence to a system of basic human rights.

Equipped with this justification of autonomy, we may now offer it to the sceptic of either the radical or the local variety. We may ask: does the sceptic of either sort have reason to resist our offer? With respect to the radical sceptic, we will have to wonder whether Dworkin's account invites the by now familiar sceptical objection: "So what if respect for human rights is morally required?" If it does, we will have to examine further whether it has the resources to motivate adequately our allegiance to human rights norms and rebut this challenge. As far as the local sceptic is concerned, we will have to assess whether Dworkin's ethical outlook is perhaps parochial in the sense that it is alien to or inappropriate for cultures that are arguably less individualistic than modern Western societies to which it seems to be better attuned. These are large questions that cannot be addressed without a more thorough analysis of Dworkin's moral theory than the one attempted here. Still, there is reason to be optimistic. For, Dworkin, no less than Alexy, starts from an idea that is at the same time both universal and captivating, the idea of living well. It is the kind of idea that can engage even the most hard-nosed sceptic, if any can.

\section{Conclusion}

Discourse theory in various fields of philosophy has a venerable tradition, and Robert Alexy is among its most distinguished torchbearers. This article did not question either its validity or its fruitfulness in general. But it did raise some doubts about its relevance for the project of finding a foundation of human rights, especially when it comes in the form of a transcendental argument. Our concern for human rights, it seems, is at once more targeted and practically engaged, more intertwined with the vexed questions of relative importance that human rights typically give rise to than such an argument can allow. Taking the example of Ronald Dworkin's theory, I have suggested that we are more likely to find the ideas we are looking for further downstream. The idea of a good life may be a good place to start. 